\title{
LEVANTAMENTO DAS PLANTAS MEDICINAIS E TÓXICAS DO CAMPUS DA UNIVERSIDADE ESTADUAL DE FEIRA DE SANTANA
}

\author{
Gabriel Barros da Silva. ${ }^{1}$; Tânia Regina dos Santos Silva ${ }^{2}$ \\ 1. Bolsista FAPESB, Graduando em Licenciatura em Ciências Biológicas, Universidade Estadual de Feira de \\ Santana, e-mail: gabrielxbarros@hotmail.com \\ 2. Orientador, Departamento de Ciências Biológicas, Universidade Estadual de Feira de Santana, e-mail: \\ taniasilva@uefs.br
}

PALAVRAS-CHAVE: semiárido; botânica; educação.

\section{INTRODUÇÃO}

O uso de plantas medicinais surgiu, segundo Almeida (2011), à medida que o homem tentava suprir suas necessidades básicas, através das casualidades, tentativas e observações, conjunto de fatores que constituem o empirismo. O homem pré-histórico diferenciava plantas comestíveis das que atualmente sabemos que possuem potencial medicinal intuitivamente ou pela observação dos animais, os quais buscavam nas ervas a cura para as suas afecções (OLIVEIRA \& SILVA, 1994). O conhecimento popular passou a ser compilado e guardado como parte da identidade cultural de muitos povos e está presente no cotidiano destas comunidades até hoje, sendo pertinente destacar que diversas organizações têm reunido esforços para implementar a prática e o uso adequado de plantas medicinais (COSTA \& GUTIÉRREZ, 2016).

O uso de plantas medicinais e a sua inclusão nos serviços de saúde vêm sendo estimulados desde a década de 1970 pela Organização Mundial da Saúde (BRANDÃO, 2009). Contudo, apenas em 1995 esforços começaram a ser empreendidos no Brasil, visando estimular os estudos com plantas medicinais. Assim, estudos científicos sobre plantas medicinais no Brasil são recentes e, apesar de toda biodiversidade, basicamente todas as plantas medicinais estudadas e usadas não pertencem à flora brasileira devido à falta de estudos científicos que comprovem suas ações (BRANDÃO, 2009).

Portanto, esta pesquisa visou o estudo científico sobre plantas medicinais e tóxicas, produzindo material didático para ser utilizado em atividades com a comunidade em geral. Esse guia contém foto, nome(s) popular(es), nome científico, e descrição sucinta sobre o uso e/ou restrição destas plantas.

\section{MATERIAIS E MÉTODOS}

Entre os meses de março de 2017 e maio de 2018 foram realizadas coletas, mapeamento, registros fotográficos e caracterização morfológica das partes vegetativas e reprodutivas, com a produção de exsicatas (secagem, prensagem e inclusão no banco de dados do Herbário da Universidade Estadual de Feira de Santana - HUEFS). As amostras foram identificadas com chaves de identificação e consultas aos especialistas das famílias botânicas. Após a identificação, houve o levantamento bibliográfico em literatura especializada para a descrição de uso e/ou restrição. O guia começou a ser editorado em janeiro de 2018 após toda a descrição de uso, das fotografias e distribuição das plantas inclusas.

\section{RESULTADOS}

Foram registradas 53 espécies alocadas em 46 gêneros e 24 famílias botânicas. Destas, 35 espécies são cultivadas, sendo utilizadas para alimentação ou ornamentação; 12 são nativas e 6 são ruderais. 


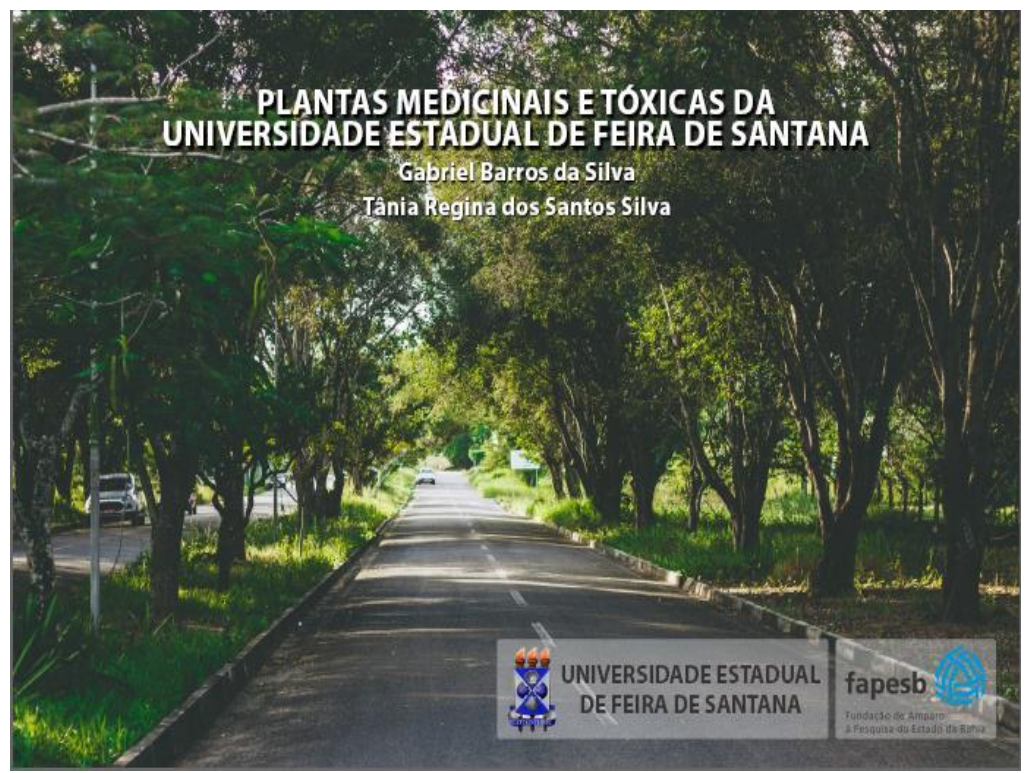

Figura 1: Capa do guia.

\section{CUCURBITACEAE}
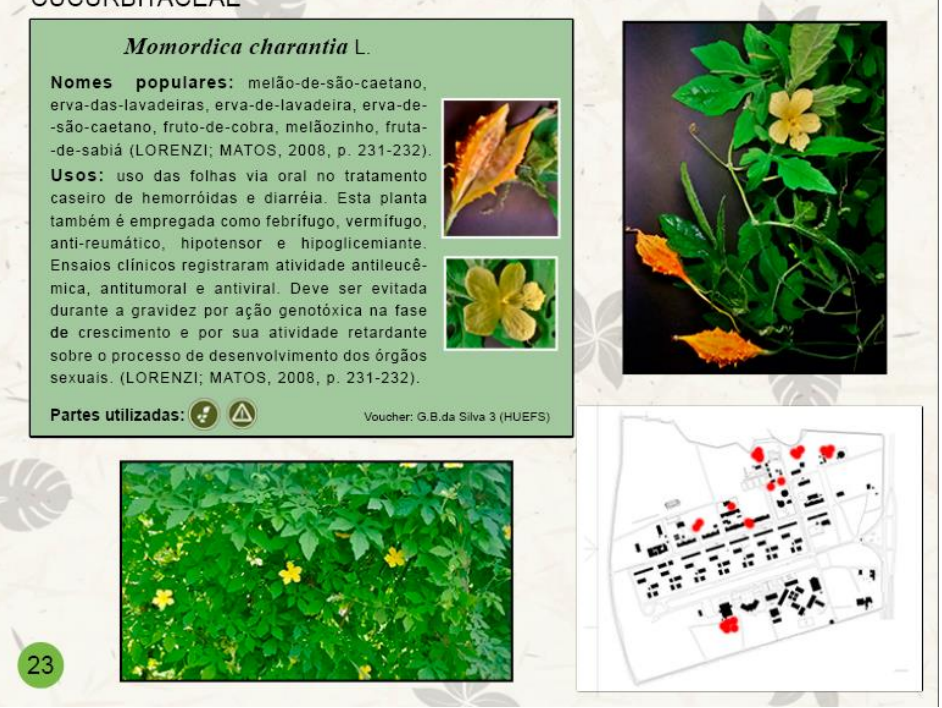

23

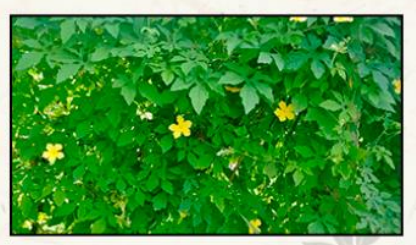

Figura 2: Página da planta Momordica charantia L. do guia.

PASSIFLORACEAE

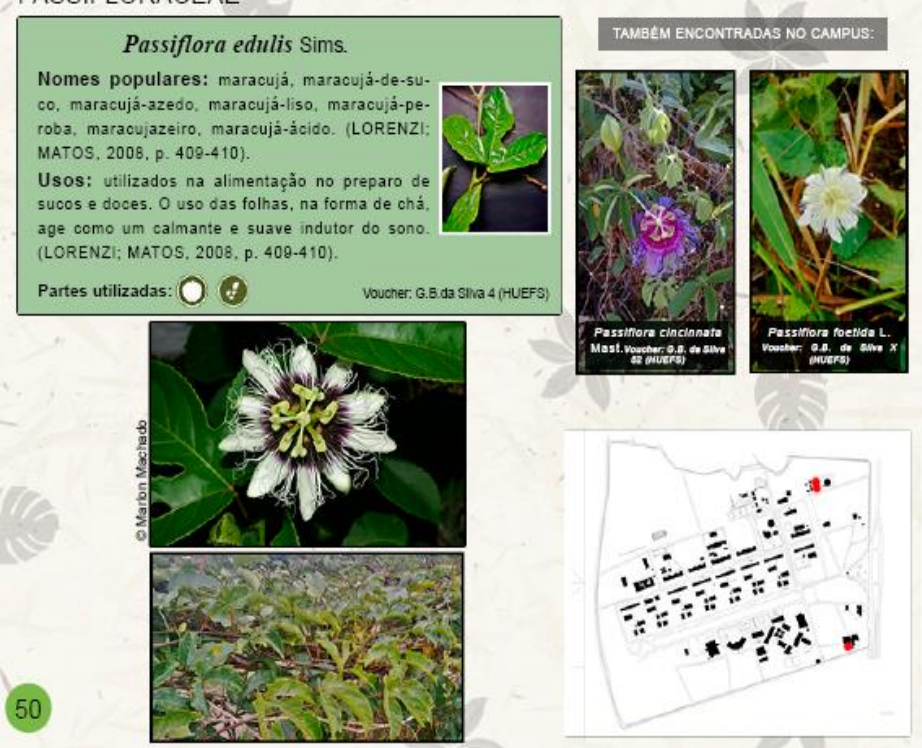

Figura 3: Página da planta Passiflora edulis Sims do guia. 
APIACEAE (UMBELLIFERAE)
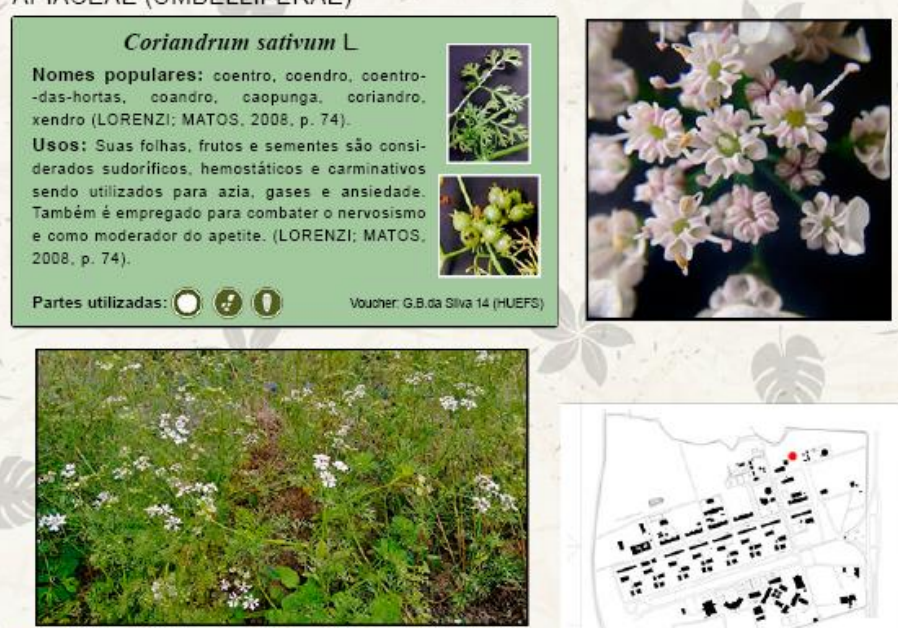

(11)

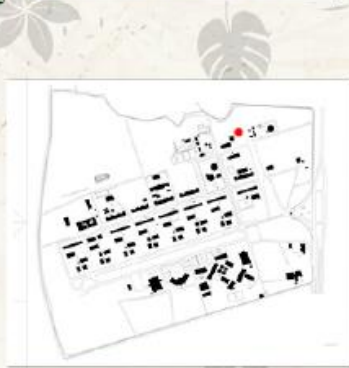

Figura 4: Página da planta Coriandrum sativum L. do guia.

ANACARDIACEAE
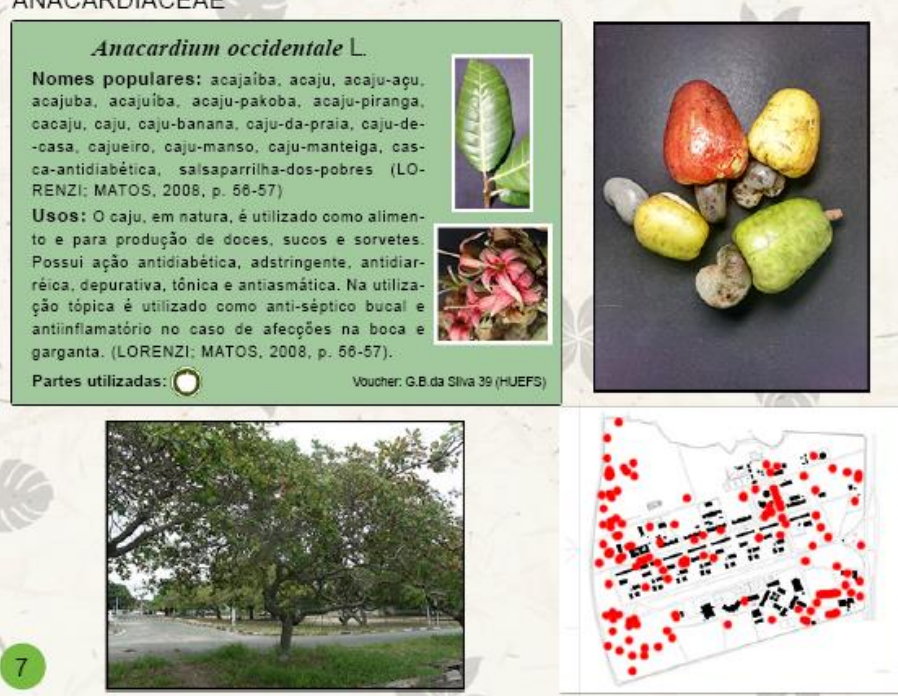

Figura 5: Página da planta Anacardium occidentale L. do guia.

ANNONACEAE
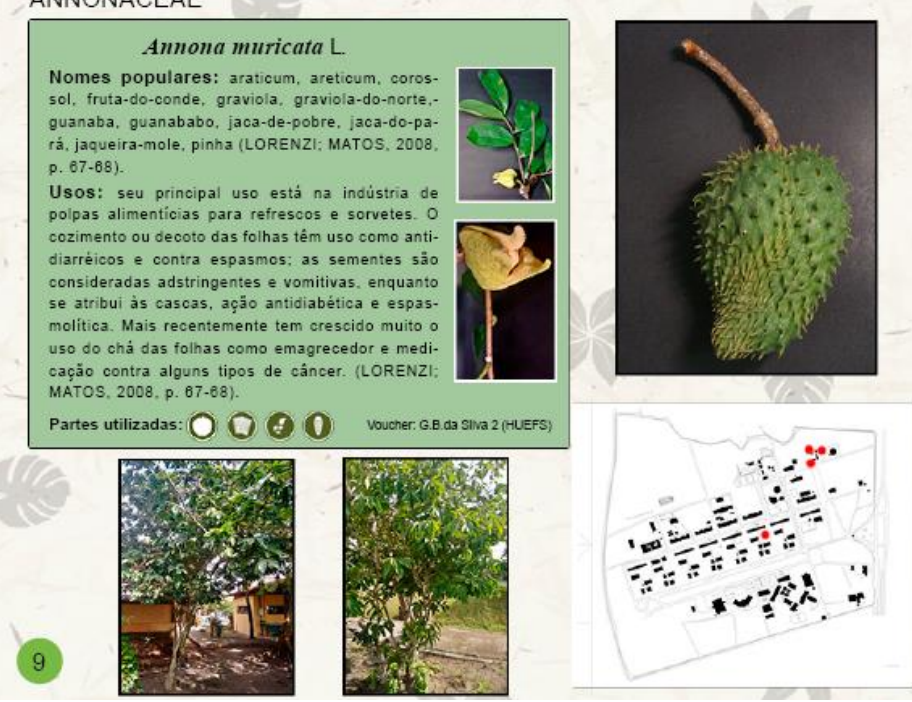

Figura 6: Página da planta Annona muricata L. do guia. 


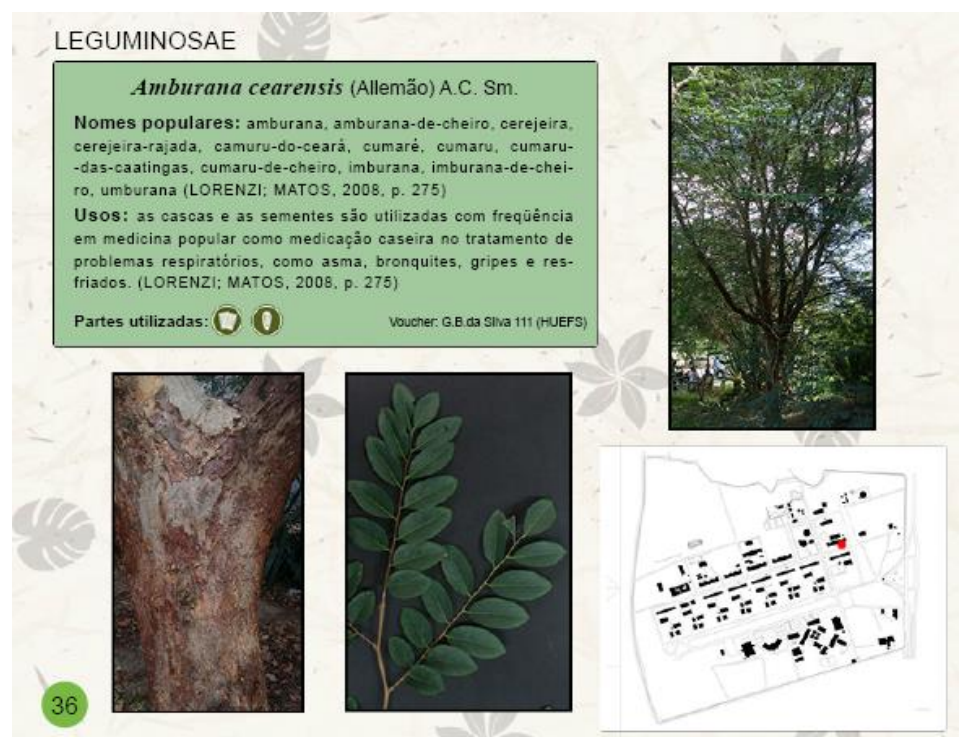

Figura 7: Página da planta Amburana cearensis (Allemão) A.C. Sm. do guia.

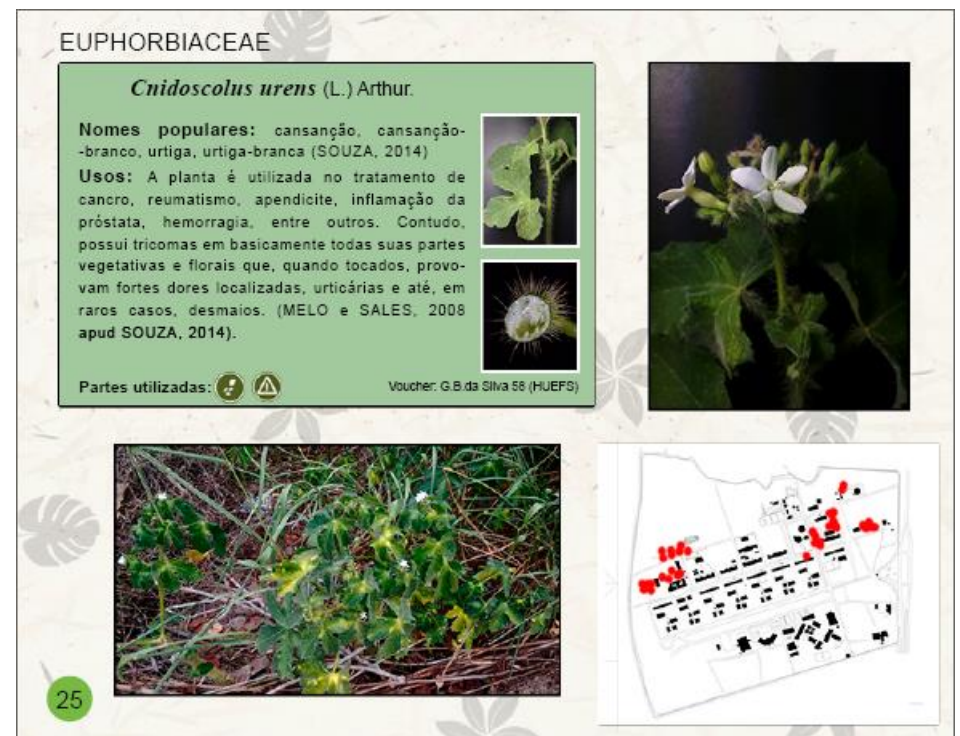

Figura 8: Página da planta Cnidoscolus urens (L.) Arthur do guia.

\section{REFERÊNCIAS}

ALMEIDA, M.Z. 2011 Plantas medicinais. 3. ed. - Salvador : EDUFBA,. 221 p.

BRANDÃO, M.G.L. 2009. Plantas medicinais e fitoterápicos (aspectos gerais e métodos de validação) - Belo Horizonte : Editora O Lutador.

COSTA, S. C. C.; GUTIÉRREZ, I.E.M. 2016. Plantas medicinais e seus usos. - Feira de Santana : UEFS Editora.

LORENZI, H.; MATOS, F. J. de A. 2008. Plantas medicinais no Brasil: nativas e exóticas. 2. ed. Nova Odessa: Instituto Plantarum, 544 p

MATOS, F.J.A. et al. 2011. Plantas Tóxicas: Estudo de Fitotoxicologia Química de Plantas Brasileiras. Nova Odessa: Plantarum, Flora, 256p.

OLIVEIRA, R.A.G; SILVA, M.S.H. 1994. Plantas medicinais na atenção primária à saúde. João Pessoa: UFPB. 